\title{
CDISC SDTM Canadian Cardiovascular Society Classification Terminology
}

National Cancer Institute

\section{Source}

National Cancer Institute. CDISC SDTM Canadian Cardiovascular Society Classification

Terminology. NCl Thesaurus. Code C101842.

Terminology associated with the Canadian Cardiovascular Society classification codelist of the Clinical Data Interchange Standards Consortium (CDISC) Study Data Tabulation Model (SDTM). 